\title{
A ENCRUZILHADA DA UNIVERSIDADE EUROPEIA
}

\author{
Boaventura de Sousa Santos
}

Ao refletirmos sobre a universidade europeia, ou mesmo sobre a universidade a nível mundial, este é um momento em que é tão importante olhar para o passado como para o futuro. No caso da Europa, encontramo-nos atualmente bem no meio do processo de Bolonha. É um período propenso a flutuações intensas entre avaliações positivas e negativas, entre o sentimento de que é ou demasiado tarde ou demasiado cedo para alcançar os resultados almejados. Na minha perspetiva, essas flutuações intensas na análise e na avaliação constituem um sinal de que tudo permanece em aberto, de que o fracasso e o sucesso pairam igualmente no horizonte e de que depende de nós fazer com que um ou o outro aconteçam. 0 grande filósofo Ernst Bloch escreveu que, para toda a esperança, há sempre um caixão: Heil e Unheil.

Apesar de o nosso objetivo principal ser refletir fundamentalmente sobre a universidade europeia, seria pouco inteligente pensar que os desafios que a universidade europeia enfrenta hoje em dia não estão presentes em todos os continentes, por mais diferentes que possam ser as razões, os argumentos e as soluções propostas.

Em geral, podemos afirmar que a universidade está a atravessar - tal como o resto das sociedades contemporâneas - um período de transição paradigmática. Esta transição pode ser caracterizada da seguinte forma: enfrentamos problemas modernos para os quais não temos soluções modernas. Muito sucintamente: os nossos problemas modernos residem na prossecução dos ideais da Revolução Francesa - liberdade, igualdade, fraternidade. Nos últimos dois séculos não fomos capazes de alcançar esses ideais, nem na Europa, nem muito menos no resto do mundo. As soluções encontradas não conseguiram concretizar os objetivos maiores pelos quais se combateu arduamente. Quando falo em soluções, refiro-me ao progresso científico e tecnológico, à racionalidade formal e instrumental, ao Estado burocrático moderno, ao reconhecimento das divisões e discriminações de classe, raça e género e à institucionalização dos conflitos sociais suscitados por elas através de processos democráticos, ao desenvolvimento de culturas e identidades nacionais, ao secularismo e ao laicismo, e assim por diante.

A universidade moderna, particularmente a partir de meados do século XIX, foi uma componente fundamental dessas soluções. Na verdade, foi à luz delas que a autonomia institucional, a liberdade académica e a responsabilidade social foram originalmente concebidas. A crise generalizada das soluções modernas arrastou consigo a crise da universidade. Nos últimos quarenta anos, por razões diferentes, mas convergentes, em diferentes partes do mundo, em vez de uma solução para os problemas societais, a universidade tornou-se um problema adicional. Depois da Segunda Guerra Mundial, o início da década de 1970 foi um período de impulsos reformistas intensos em todo o mundo. Na maioria dos casos, foram motivados pelos movimentos estudantis dos finais dos anos 1960 e do início dos anos 1970.

No que diz respeito à universidade, o problema pode ser formulado desta maneira: a universidade está a ser confrontada com perguntas fortes, para as quais não forneceu, até ao momento, mais do que respostas fracas. As perguntas fortes são perguntas que atingem as raízes da própria identidade histórica e da vocação da universidade, de modo a interrogar não tanto os pormenores do seu futuro, mas antes se a universidade, tal como a conhecemos, terá 
realmente um futuro. São, por isso, perguntas que suscitam um tipo particular de perplexidade.

As respostas fracas tomam o futuro da universidade por garantido. As reformas a que apelam acabam por ser um convite ao imobilismo. As respostas fracas não atenuam a perplexidade suscitada pelas perguntas fortes, podendo, pelo contrário, aumentá-la. Na realidade, estas respostas fracas partem do princípio de que a perplexidade é inútil.

Como proponho e aprofundo mais adiante, devemos aproveitar as perguntas fortes e transformar a perplexidade que estas provocam em energia positiva de modo a aprofundar e reorientar o movimento reformista. A perplexidade resulta do facto de nos encontrarmos perante um campo aberto de contradições, no qual existe uma competição inacabada e desregulada entre diferentes possibilidades. Mostrando a magnitude do que está em causa, estas possibilidades abrem espaço para a inovação política e institucional.

\section{Perguntas fortes}

Apresento seguidamente alguns exemplos das perguntas fortes com que se confronta a universidade no início do século XXI. Sem pretender ser exaustivo, seleciono doze destas perguntas.

Primeira pergunta forte: dado o facto da universidade ter funcionado como elemento constitutivo do edifício do Estado-Nação moderno - formando as respetivas elites e burocracia e fornecendo o conhecimento e a ideologia subjacentes ao projeto nacional - como pode a missão da universidade ser refundada em um mundo globalizado, um mundo no qual a soberania do Estado é, cada vez mais, uma soberania partilhada ou simplesmente uma escolha entre tipos diferentes de dependência, e na qual a própria ideia de um projeto nacional se tornou um obstáculo para as conceções dominantes de desenvolvimento global? Será a universidade global uma resposta possível? Nesse caso, quantas dessas universidades globais seriam viáveis? 0 que aconteceria ao grande número das universidades restantes? Se se pretendesse que as elites globais fossem formadas nas universidades globais, onde se encontrariam, na sociedade, os aliados e a base social para as universidades não globais? Que tipo de relações haveria entre universidades globais e não globais? Poderá a atenção focalizada nos rankings contribuir para a coesão do espaço do ensino superior europeu ou, pelo contrário, para a sua segmentação através de uma concorrência injusta e do crescimento do internacionalismo comercial?

Uma segunda pergunta forte pode ser formulada assim: a ideia de uma sociedade do conhecimento implica que o conhecimento está em todo o lado; qual é o impacto desta ideia numa universidade moderna criada sobre o pressuposto de que constituía uma ilha de saber numa sociedade de ignorância? Qual é o lugar ou a especificidade da universidade como um centro de produção e difusão do conhecimento numa sociedade com muitos outros centros de produção e difusão do conhecimento? Ou, pelo contrário, poderão as novas tecnologias de produção e disseminação do conhecimento (internet ebook, ejournal, elibraries, etc.) minar as práticas tradicionais e elitistas de gate-keeping na publicação de livros e revistas científicas e académicas, possibilitando novas práticas de peer reviewing, mais equalitárias, culturalmente sensíveis e paradigmaticamente liberais? Continuará a avaliação do trabalho académico a ser feita com base em critérios monoculturais e muitas vezes antiquados de boa escrita científica, rigor metodológico ou solidez teórica, aplicados frequentemente por colegas ressentidos, concorrrentes ou com conflitos de interesses?

Terceira pergunta forte: No seu melhor, a universidade moderna foi um lugar de pensamento livre e independente e de celebração da diversidade, mesmo se sujeita aos limites estreitos das disciplinas, quer nas ciências, quer nas humanidades. Tendo em conta que, nos últimos trinta anos, a tendência para transformar o valor do conhecimento no valor de mercado do conhecimento se tornou cada vez mais forte, poderá haver algum futuro para um 
conhecimento não-conformista, crítico, heterodoxo, não mercantilizável, bem como para os professores, investigadores e estudantes que desenvolverem este tipo de conhecimento? Se sim, qual seria o seu impacto sobre os critérios de excelência e de competitividade interuniversitária? Se não, poderemos continuar a chamar universidade a uma instituição que produza apenas conformistas competentes, e jamais rebeldes competentes, e que considere 0 conhecimento exclusivamente como uma mercadoria e nunca como um bem público?

Quarta pergunta forte: A universidade moderna foi, desde o início, uma instituição transnacional ao serviço de sociedades nacionais. No seu melhor, a universidade moderna é um modelo pioneiro dos fluxos internacionais de ideias, professores, estudantes e livros. Vivemos num mundo globalizado, mas não num mundo homogeneamente globalizado. Existem não apenas lógicas diferentes que determinam o movimento dos fluxos globalizados, mas também diferentes relações de poder por detrás da distribuição dos custos e dos benefícios da globalização. De par com a ganância transnacional existe uma solidariedade transnacional. De que lado estará a universidade? Tornar-se-á numa empresa transnacional ou numa cooperativa ou organização sem fins lucrativos transnacional? Existe alguma contradição entre a nossa ênfase no desenvolvimento cultural e social e a ênfase de alguns políticos europeus e de think-tanks poderosos no desenvolvimento económico e a contribuição da universidade para a competitividade global dos negócios europeus? Que razão levou a que alguns dos melhores esforços reformistas fora da Europa (por exemplo, no Brasil) a adotarem o slogan: "Nem Bolonha nem Harvard"?

Quinta pergunta forte: A longo prazo, a ideia da Europa só será sustentável como a Europa das ideias. Ora, a universidade tem sido historicamente um dos pilares da Europa das ideias, por mais questionáveis que essas ideias possam ter sido. Isto foi possível através da concessão à universidade de um grau de autonomia inimaginável em qualquer outra instituição estatal. o lado negativo desta autonomia foi o isolacionismo social, a falta de transparência, a ineficiência organizacional, um prestígio social desligado das realizações académicas. Segundo o seu desígnio original, o processo de Bolonha devia ter posto fim a este lado negativo sem afetar significativamente a autonomia da universidade. Será que este desígnio tem sido levado a cabo sem resultados perversos? Será que o processo de Bolonha é uma rutura com os aspetos negativos da universidade tradicional, ou, pelo contrário, um brilhante exercício de reordenação de inércias e reciclagem de antigos vícios? Será possível estandardizar procedimentos e critérios abrangendo tantas culturas universitárias diferentes sem aniquilar a diversidade e a inovação? Será possível promover a transparência, a mobilidade e o reconhecimento mútuo, preservando a diversidade institucional e cultural? Por que razão as boas ideias e os ideais nobres são tão facilmente cooptados pelos burocratas?

Sexta pergunta forte: o prestígio do emprego vai de par com a qualificação e escassez do mesmo. A universidade moderna tem estado no cerne da produção social de elevadas qualificações de emprego. Se os rankings conseguirem fragmentar o sistema universitário europeu e o futuro sistema universitário global, que empregos e que qualificações serão gerados por que universidades? O sistema mundial está construído sobre uma hierarquia integrada de países do centro, países periféricos e países semiperiféricos. A presente crise financeira e económica tem mostrado que a mesma hierarquia existe na Europa e, como tal, a coesão social tem revelado o seu lado negativo: existe na condição de não afetar a hierarquia estrutural, de que os países se mantenham centrais, periféricos ou semiperiféricos, sem ascenderem nem descerem na hierarquia. Será que teremos universidades periféricas, semiperiféricas e centrais, mesmo que estas não coincidam necessariamente com a localização na hierarquia dos países nos quais se situam? Será que o processo de Bolonha vai tornar essas hierarquias mais rígidas ou mais fluidas? Dependendo da distribuição geopolítica dos rankings, será que a hierarquia entre as universidades contribuirá para acentuar ou atenuar as hierarquias entre países europeus?

Sétima pergunta forte: À medida que a universidade diversifica os graus de qualificação primeiro, segundo e terceiro ciclos e graus de pós-doutoramento - a iliteracia social aumenta nos graus inferiores, justificando assim o maior valor dos graus mais elevados. De facto, tratase de um movimento em espiral. Terá já esgotado o seu potencial de desenvolvimento? Quantos ciclos mais teremos no futuro? Estaremos a criar iliteracia infinita no mesmo 
processo em que criamos conhecimento infinito? Será que as universidades periféricas e semiperiféricas ficarão encarregadas de resolver o problema da iliteracia, ficando o monopólio do conhecimento altamente qualificado reservado às universidades centrais?

Oitava pergunta forte: Será que a universidade poderá preservar a sua especificidade e a sua autonomia relativa, sendo governada por imperativos de mercado e pelas exigências do mercado de trabalho? Tendo em conta a validade altamente problemática da análise custobenefício no domínio da investigação e desenvolvimento, será que a universidade terá a possibilidade de assumir custos certos na expectativa de lucros incertos, tal como sempre fez no passado? 0 que acontecerá ao saber que não tem e não deve ter valor de mercado? No que diz respeito ao conhecimento comercializável, qual o impacto que será exercido sobre ele se esse conhecimento for avaliado exclusivamente segundo o respetivo valor de mercado? Qual será o futuro da responsabilidade social se a extensão universitária for reduzida a um expediente ou a um fardo para angariar recursos financeiros? 0 que acontecerá ao imperativo de tornar a universidade relevante para as necessidades da sociedade, partindo do princípio de que essas necessidades não se reduzem às do mercado e podem até contradizê-las?

Nona pergunta forte: A universidade (ou pelo menos a universidade pública) inseriu-se historicamente nos três pilares da regulação social moderna - o Estado, o mercado e a sociedade civil. Contudo, o equilíbrio da presença destes pilares na estrutura e funcionamento da universidade foi variando ao longo do tempo. Na verdade, a universidade europeia moderna começou em Bolonha, como uma iniciativa da sociedade civil. Mais tarde, o Estado reforçou a sua presença, que se tornou dominante a partir de meados do século XIX, e nas colónias, particularmente depois de se tornarem independentes. Nos últimos trinta anos, o mercado assumiu o controlo na estruturação da vida universitária. Em poucas décadas, a universidade deixou apenas de produzir conhecimento e profissionais para o mercado, para se tornar ela própria um mercado, o mercado da educação terciária, e finalmente, pelo menos de acordo com visionários poderosos, para passar a ser gerida como uma organização de mercado, uma organização comercial. Desde então, as preocupações da sociedade civil têm sido facilmente confundidas com os imperativos de mercado ou subordinadas a eles, e o Estado tem usado frequentemente o seu poder coercivo para impor imperativos de mercado às universidades relutantes. Será que o processo de Bolonha é uma resposta criativa a exigências neo-liberais, unidimensionais ou, pelo contrário, uma maneira de as impor através de um processo europeu transnacional que neutralize a resistência nacional?

Décima pergunta forte: as universidades europeias e muitas outras universidades no resto do mundo que seguiram o modelo europeu foram instrumentais na disseminação de uma mundivisão eurocêntrica, uma visão suficientemente poderosa (tanto em termos intelectuais como militares) para reivindicar uma validade universal. Esta reivindicação não implicava ignorar as diferenças culturais, sociais e espirituais do mundo não-europeu. Pelo contrário, pressupunha o conhecimento dessas diferenças, mesmo que sujeito a objetivos eurocêntricos, fossem eles a celebração romântica do Outro ou a subjugação colonial e destruição desse Outro. Em ambos os casos, o conhecimento do Outro tinha como função demonstrar a superioridade e, por conseguinte, a universalidade da cultura europeia. Era imprescindível um conhecimento detalhado, colonial ou imperial do Outro. Por exemplo, a minha universidade, a Universidade de Coimbra, fundada em 1290, contribuiu de forma determinante para o desenvolvimento de um conhecimento empenhado na empresa colonial. A qualidade e a intensidade do trabalho preparatório desenvolvido pelos missionários antes do embarque para além-mar é impressionante, e ainda mais admirável quando comparado com o trabalho preparatório dos executivos do Banco Mundial e do Fundo Monetário Internacional quando evangelizam o mundo com a ortodoxia neoliberal nas cabeças e nas algibeiras. Do conhecimento que estes pretendem ter não se pode dizer aquilo que o grande líder dos movimentos de libertação africanos, Amílcar Cabral, afirmou sobre o conhecimento colonial: "A procura desse conhecimento, apesar do seu cariz unilateral, subjetivo e muitas vezes injusto, contribui de facto para enriquecer as ciências humanas e sociais em geral".

A décima primeira questão é a seguinte: Estará a universidade preparada para reconhecer que a compreensão do mundo vai muito além da compreensão ocidental do mundo? Será que a universidade está preparada para refundar a ideia de universalismo numa nova base 
intercultural? Vivemos num mundo de normas em conflito e muitas delas têm conduzido à guerra e à violência. As diferenças culturais, as identidades coletivas novas e velhas, as conceções e convicções políticas, religiosas e morais antagonísticas são hoje mais visíveis do que nunca, tanto fora como dentro da Europa. Não há nenhuma alternativa à violência que não passe pela disponibilidade para aceitar a incompletude de todas as culturas e identidades, incluindo a nossa, por negociações árduas, e por um diálogo intercultural credível. Se a Europa, contra o seu próprio passado, se quiser tornar um farol da paz, do respeito pela diversidade e pelo diálogo intercultural, a universidade terá certamente um papel fundamental a desempenhar. Será que as universidades europeias submetidas atualmente a processos de reforma têm em mente esse papel como um objetivo estratégico do seu futuro?

A décima segunda pergunta, provavelmente a mais forte de todas, é a seguinte: as universidades modernas têm sido simultaneamente produtos e produtoras de modelos específicos de desenvolvimento. Quando o processo de Bolonha se iniciou havia mais certezas sobre o projeto de desenvolvimento europeu do que há atualmente. 0 efeito cumulativo de crises múltiplas - a crise económica e financeira, a crise ambiental e energética, a crise do modelo social europeu, a crise das migrações, a crise da segurança - aponta para uma crise civilizacional ou para uma mudança paradigmática. A pergunta é: num período tão tumultuoso, será que é possível a universidade manter-se serena? E, se for possível, será que é desejável? Será que o processo de Bolonha está a capacitar a universidade para entrar no debate sobre modelos de desenvolvimento e paradigmas civilizacionais, ou, pelo contrário, estará a moldá-la para servir de um modo tão acrítico e eficiente quanto possível o modelo dominante decidido pelos poderes instituídos e avaliado pelos novos supervisores da produção universitária, a mando dos mesmos poderes?

A nível internacional, dado o conflito entre conceções locais de desenvolvimento autónomo e o modelo de desenvolvimento global imposto pelas regras da Organização Mundial do Comércio, e tendo em conta o facto de os estados europeus serem estados doadores, será que a universidade poderá contribuir para um diálogo entre modelos diferentes de desenvolvimento? Ou, pelo contrário, será que a universidade fornecerá legitimidade intelectual a imposições unilaterais dos estados doadores, tal como acontecia no período colonial?

\section{O presente como o passado do futuro}

Na minha perspetiva, até agora, uma década depois do início do processo de Bolonha, não conseguimos fazer mais do que dar respostas fracas a estas perguntas fortes. As mais fracas de todas são as não-respostas, os silêncios, o assumir do novo senso comum sobre a missão da universidade como um pressuposto definitivo. Esta é uma situação que devemos ultrapassar o mais rapidamente possível. 0 perigo é mascararmos conquistas realmente medíocres para parecerem brilhantes saltos em frente, disfarçarmos a resignação sob a máscara do consenso, orientarmos a universidade no sentido de um futuro em que não há futuro para a universidade. Creio que nos encontramos numa encruzilhada que os nossos cientistas da complexidade caracterizariam como uma situação de bifurcação. Movimentos mínimos numa direção ou noutra podem produzir alterações significativas e irreversíveis. Tal é a magnitude da nossa responsabilidade. Sabemos que nunca agimos sobre o futuro; agimos sobre o presente à luz das nossas previsões ou visões do que será o futuro. As perguntas fortes indicam que não há uma previsão única ou visão consensual que se possa considerar garantida, e é por isso que estas questões nos convidam para uma reflexão profunda.

Penso que nos encontramos perante duas visões alternativas e que a sua copresença é a fonte das tensões que atravessam o nosso sistema universitário atualmente. Suscitam duas visões imaginárias opostas de uma avaliação retrospetiva das reformas em curso. Isto é, olham para o presente a partir do futuro. 
Segundo uma delas, os nossos esforços de reforma constituíram, de facto, uma verdadeira reforma, na medida em que conseguiram preparar a universidade para enfrentar com eficiência os desafios do século XXI - diversificando a sua missão, sem prescindir da sua autenticidade, reforçando a autonomia institucional, a liberdade académica e a responsabilidade social no quadro das condições novas e muito complexas da Europa e do mundo em geral. Assim, a universidade europeia foi capaz de refundar o seu ideal humanista de um modo internacionalista, solidário e intercultural.

Segundo a outra visão retrospetiva imaginária, o processo de Bolonha foi, pelo contrário, uma contrarreforma, na medida em que bloqueou as reformas que as universidades, em diferentes países europeus, estavam a levar a cabo individualmente, e cada uma segundo as respetivas condições específicas, no sentido de enfrentarem os desafios acima mencionados. Mais: o processo de Bolonha forçou uma convergência para lá de um nível razoável, com o que retirou à universidade os mecanismos que the permitiriam resistir aos imperativos do mercado e dos negócios da mesma maneira que, no passado, resistira aos imperativos da religião e, mais tarde, do Estado.

De modo a não finalizar com uma nota pessimista, vou começar por descrever detalhadamente a segunda visão retrospetiva, e passar seguidamente à primeira. A segunda visão, a visão da contrarreforma, coloca-nos perante um cenário distópico com as características seguintes:

Agora que a crise financeira permitiu ver os perigos de criar uma moeda única sem unificar as políticas públicas, a fiscalidade e os orçamentos do Estado, pode suceder que, a prazo, o processo de Bolonha se transforme no euro das universidades europeias. As consequências previsíveis serão estas: abandonam-se os princípios do internacionalismo universitário solidário e do respeito pela diversidade cultural e institucional em nome da eficiência do mercado universitário europeu e da competitividade; as universidades mais débeis (concentradas nos países mais débeis) são lançadas pelas agências de rating universitário no caixote do lixo do ranking, tão supostamente rigoroso quanto realmente arbitrário e subjetivo, e sofrerão as consequências do desinvestimento público acelerado; muitas universidades encerrarão e, tal como já está a acontecer a outros níveis de ensino, os estudantes ricos e seus pais vaguearão pelos países em busca da melhor ratio qualidade/preço, tal como já fazem nos centros comerciais em que as universidades entretanto se terão transformado, enquanto os estudantes pobres e os seus pais se verão limitados às universidades pobres existentes nos respetivos países ou bairros pobres.

O impacto interno será avassalador: a relação investigação/docência, tão proclamada por Bolonha, será o paraíso para as universidades no topo do ranking (uma pequeníssima minoria) e o inferno para a esmagadora maioria das universidades e respetivos académicos. Os critérios de mercantilização reduzirão o valor das diferentes áreas de conhecimento ao seu preço de mercado e o latim, a poesia ou a filosofia só serão mantidos se algum macdonald informático vir neles utilidade. Os gestores universitários serão os primeiros a interiorizar a orgia classificatória, objectivomaníaca e indicemaníaca; tornar-se-ão exímios em criar receitas próprias por expropriação das famílias ou pilhagem do descanso e da vida pessoal dos docentes, exercendo toda a sua criatividade na destruição da criatividade e da diversidade universitárias, normalizando tudo o que é normalizável e destruindo tudo o que o não é. Os professores serão proletarizados por aquilo de que supostamente são donos - o ensino, a avaliação e a investigação - zombies de formulários, objetivos, avaliações impecáveis no rigor formal e necessariamente fraudulentas na substância, workpackages, deliverables, milestones, negócios de citação recíproca para melhorar os índices, comparações entre o publicas-onde-não-me-interessa-o-quê, carreiras imaginadas como exaltantes e sempre paradas nos andares de baixo. Para os docentes mais jovens, a liberdade académica não passará de uma piada cruel. Os estudantes serão donos da sua aprendizagem e do seu endividamento para o resto da vida, em permanente deslize da cultura estudantil para cultura do consumo estudantil, autónomos nas escolhas de que não conhecem a lógica nem os limites, personalizadamente orientados para as saídas de uma alternativa massificada de emprego ou de desemprego profissional. 
O serviço da educação terciária estará finalmente liberalizado e conforme às regras da Organização Mundial do Comércio. Como já disse, nada do que acabei de descrever tem de acontecer. Há uma outra visão retrospetiva que, nos nossos corações e nas nossas mentes, temos muita esperança que venha a prevalecer. Porém, para que tal aconteça, temos de começar por reconhecer e denunciar que a suposta nova normalidade do estado de coisas da descrição acima constitui, de facto, uma aberração moral, e implicará o fim da universidade, tal como a conhecemos.

Consideremos agora a outra visão retrospetiva, aquela que, olhando para o nosso presente a partir do futuro, avalia o processo de Bolonha como uma verdadeira reforma que alterou a universidade europeia profundamente e para melhor. Esta visão enfatizará as seguintes características dos nossos esforços atuais.

Em primeiro lugar, o processo de Bolonha foi capaz de identificar e resolver a maioria dos problemas de que a universidade pré-Bolonha sofria e que era incapaz de defrontar, tais como: inércias estabelecidas que paralisavam todo e qualquer esforço reformista; preferências endogâmicas que criavam aversão à inovação e ao desafio; autoritarismo institucional disfarçado de autoridade académica; nepotismo disfarçado de mérito; elitismo disfarçado de excelência; controlo político disfarçado de participação democrática; neofeudalismo disfarçado de autonomia departamental ou de faculdade; temor da avaliação disfarçado de liberdade académica; baixa produção científica disfarçada de resistência heroica a termos de referência estúpidos ou a comentários ignorantes de avaliadores; ineficiência administrativa generalizada sob o disfarce de respeito pela tradição.

Em segundo lugar, desta maneira, o processo de Bolonha, em vez de ter desacreditado e atirado borda fora os esforços de autoavaliação e de reforma que estavam a ser levados a cabo pelos professores e administradores mais dedicados e inovadores, forneceu-lhes um novo quadro e um apoio institucional forte, na medida em que o processo de Bolonha se converteu numa energia endógena, em vez de constituir uma imposição externa. De modo a conseguir tudo isto, o processo de Bolonha foi capaz de combinar convergência com diversidade e diferença, e desenvolveu mecanismos de discriminação positiva para permitir aos diferentes sistemas universitários nacionais cooperar e competir entre si em termos justos.

Em terceiro lugar, o processo de Bolonha nunca se deixou dominar pelos chamados peritos internacionais do ensino terciário com a capacidade de transformar preferências subjetivas e arbitrárias em verdades autoevidentes e políticas públicas inevitáveis. Nesta visão, o processo de Bolonha manteve em vista duas perspetivas intelectuais poderosas da missão da universidade produzidas nos primeiros anos do século passado e, inequivocamente, tomou partido entre as duas. Uma foi formulada por Ortega y Gasset e Bertrand Russel, dois intelectuais com ideias políticas muito diferentes, mas que convergiram na denúncia da instrumentalização política da universidade. A outra, formulada por Martin Heidegger na sua aula inaugural como reitor da Universidade de Freiburg im Breisgau em 1933, exortava a universidade a contribuir para preservar a força alemã da terra e do sangue. 0 processo de Bolonha adotou inequivocamente a primeira e recusou a segunda.

Em quarto lugar, os reformistas nunca confundiram o mercado com a sociedade civil ou com a comunidade e lutaram para que a universidade mantivesse uma conceção alargada de responsabilidade social, encorajando a investigação-ação, bem como os projetos de extensão com o objetivo de melhorar as vidas dos grupos sociais mais vulneráveis, presos nas armadilhas da desigualdade e da discriminação social sistémicas, tais como as mulheres, os desempregados, os jovens e os idosos, os trabalhadores migrantes, as minorias étnicas e religiosas, etc.

Quinto, o processo de reforma tornou muito claro que as universidades são centros de produção de conhecimento no sentido mais alargado possível. Neste sentido, promoveu a interculturalidade, a heterodoxia e o empenhamento crítico da melhor tradição liberal que a universidade pré-Bolonha havia abandonado em nome do política ou economicamente correto. Na mesma linha, encorajou o pluralismo científico interno e, o que é ainda mais importante, garantiu dignidade e importância iguais ao conhecimento com valor de mercado 
e ao conhecimento sem qualquer possível valor de mercado. Para além disso, os reformistas sabiam claramente, durante todo o processo, que, no domínio da investigação e desenvolvimento, a análise custo / benefício é um instrumento muito grosseiro que pode matar a inovação em vez de a promover. De facto, a história da tecnologia mostra amplamente que as inovações com maior valor instrumental se tornaram possíveis porque não houve preocupação com cálculos de custo / benefício.

Sexto, o processo de Bolonha conseguiu reforçar a relação entre docência e investigação e, ao mesmo tempo que premiava a excelência, garantiu que a comunidade de professores universitários não seria dividida entre dois segmentos estratificados: um pequeno grupo de cidadãos universitários de primeira classe, com dinheiro em abundância, cargas de serviço docente muito leves e outras boas condições para fazer investigação, por um lado, e, por outro lado, um grande grupo de cidadãos universitários de segunda classe escravizados por longas horas de docência e tutoria, com escasso acesso a fundos de investigação, apenas porque foram contratados pelas universidades erradas ou se interessavam por assuntos supostamente errados. Conseguiu combinar uma seletividade mais elevada no recrutamento e uma prestação de contas rigorosa no uso do tempo de docência e dos fundos de investigação com uma preocupação real pela igualdade de oportunidades. Compreendeu os rankings como o sal na comida: a menos, torna-a intragável; a mais, mata todos os sabores. Para além disso, num dado momento, decidiu que aquilo que acontecera nos rankings internacionais de outras áreas também podia ser aplicado ao sistema universitário. Por isso, tal como o PIB coexiste com o índice de desenvolvimento humano do PNUD, o processo de Bolonha foi capaz de introduzir pluralidade interna nos sistemas de ranking.

Sétimo, o processo de Bolonha acabou por abandonar o conceito de capital humano, outrora em voga, depois de ter concluído que as universidades deviam formar seres humanos e cidadãos completos e não um mero capital humano sujeito às flutuações do mercado tal como qualquer outro tipo de capital. Isto teve um impacto decisivo nos curricula e na avaliação das atividades. Mais: o processo de Bolonha conseguiu convencer a União Europeia e os estados europeus de que deviam ser mais generosos financeiramente com as universidades públicas, não devido a pressões corporativistas, mas antes porque o investimento num sistema universitário público de excelência é provavelmente a melhor maneira de investir no futuro de uma Europa das ideias, a única maneira de a Europa permanecer verdadeiramente europeia.

Finalmente, o processo de Bolonha expandiu exponencialmente a internacionalização da universidade europeia, mas teve o cuidado de promover outras formas de internacionalismo, em vez do internacionalismo comercial. Desta maneira, o espaço europeu do ensino superior deixou de ser uma ameaça à liberdade académica e à autonomia intelectual das universidades em todo o mundo para se tornar um aliado leal e político na manutenção das ideias de liberdade académica, autonomia institucional e diversidade de conhecimento bem vivas e saudáveis num mundo ameaçado pelo pensamento único dos imperativos de mercado.

Acabei de vos apresentar duas visões alternativas do nosso futuro. Não tenho qualquer dúvida de que todos nós desejamos que este venha a ser moldado pela segunda visão retrospetiva. Está nas nossas mãos concretizar esse objetivo.

[1] Professor Catedrático Jubilado da Faculdade de Economia da Universidade de Coimbra, Distinguished Legal Scholar da Universidade de Wisconsin-Madison e Global Legal Scholar da Universidade de Warwick.

[2] Conferência proferida no colóquio realizado por ocasião do XXII Aniversário da Magna Charta Universitatum, que teve lugar na Universidade de Bolonha, em 16 de setembro de 2010. 